\title{
Research of the Management to Promote
}

\section{Enterprise Knowledge Sharing}

\author{
Shufang Dong \\ School of Business Management, Shandong University of Finance, Jinan 250014, China \\ Tel: 86-531-8291-1089 E-mail: dsf1119@163.com
}

\begin{abstract}
Knowledge is the essential source of enterprise competitive predominance. As viewed from the explicit knowledge and tacit knowledge, it is demonstrated that the information technology is the effective method to promote explicit knowledge sharing and the human communication is the effective management practice to promote tacit knowledge sharing.
\end{abstract}

Keywords: Explicit knowledge, Tacit knowledge, Knowledge sharing

The source of enterprise competitive predominance is the focal problem concerned by the academe all along. From "enterprise resource basic viewpoint" to "core competitive ability", and up to "enterprise knowledge basic viewpoint", as the essential source of enterprise competitive predominance, knowledge has gradually turned into scholars' consensuses.

Knowledge mainly includes two types, explicit knowledge and tacit knowledge. The explicit knowledge is the knowledge which can be clearly expressed by language, letter, data, chart and formula, which possesses characteristics of standardization and systematization, and is easy to communicate and share, and generally includes product appearance, document, data base, instruction, consensuses, computer program and other forms. The tacit knowledge is the knowledge with high individualization, which possesses the character that is difficult to be standardized, and always roots in the behavior itself and is not easy to share with others, and generally exists through individual experience, team privity, technical knack, organizational culture and other forms. Thinking mode, belief, viewpoint and value view also belong to tacit knowledge. The core of knowledge management is to create a sort of mechanism and platform which can make tacit knowledge interact with explicit knowledge.

Because explicit knowledge and tacit knowledge respectively possesses different characters, so enterprise should respectively adopt different measures to promote enterprise knowledge sharing.

\section{The management practice to promote explicit knowledge sharing}

The explicit knowledge possesses characteristics of standardization and systematization, and the rapid development of information technology makes knowledge collection, sharing and application become more rapid and high effective. Through analysis and induction, the application of information technology in the explicit knowledge sharing mainly includes following forms.

(1) Interior network. Interior network is the network in the interior of the enterprise based on the information technology. It can connect the units with employees in the organizational interior and promote the sharing and flow of knowledge. Many large enterprises have established their own interior networks.

(2) Knowledge database. Knowledge database is the "repertory" of knowledge and information which stores in the enterprise by means of text or multimedia, and employees can input or export knowledge from the database. For example, the Notes database of Woodhouse Company not only collects various experiences, selective technical schemes and various sorts of knowledge used to support decisions, but also classifies thousands upon thousands information and knowledge through mode identification, optimal arithmetic and artificial intelligence, and offers decision supports and effectively combines with the expert system at the same time. Employees can get optimal operation method, expert advices, basic standard research, exertion assistant and performance measurement at any moment.

(3) Electric forum. Electric forum is the dummy space which employees can ask and answer on the interior network, and it can effectively promote the communication and knowledge transfer among employees. For example, through the "ask and answer" in the AT\&T technical forum, employees can write questions what they don't know or data they need, and leaders sometimes also write some questions, and experts will put forward solutions aiming at all problems, and in order to fully inspire the learning efficiency of the community, $30 \%$ of problems will be answered by other members first. 
(4) Knowledge map. Knowledge map is the repertory catalog of enterprise knowledge, which tells employees the knowledge projects and their distribution positions in the organization so that employees can locate the knowledge resource what they need by following up a clue. For example, the knowledge map of the Microsoft Company fully utilizes the digital technology and establishes good index system. The user can search through key words, topic and contrast, and get knowledge and employee data at any time and place through the network.

(5) E-mail. The E-mail can realize the real-time communication among employees and enhance the efficiency of communication.

\section{The management practice to promote tacit knowledge sharing}

Comparing with explicit knowledge, the tacit knowledge more depends on the communication among individuals. The spread of the tacit knowledge is decided by space distance, knowledge distance, cultural distance and absorption ability. The closer space distance, smaller knowledge difference and more communication are helpful to share the tacit knowledge.

(1) Conference and forum. Through performing conferences and forums with various topics periodically, enterprise can realize knowledge sharing through formal and informal individual communications in the conference or forum. More communications will produce more talking and stimulate employees' sixth senses, intuitions, thinker modes, beliefs, experiences and other tacit knowledge, and make for the speed of "exteriority" and "socialization".

(2) Cross-functional team. The cross-functional team is generally composed by employees from different departments, and it is a sort of organizational form independently existing for completing certain project or plan. For example, the mini-copycat of Cannon Company, here, members in the project group can fully communicate and air their own views, and some good originalities and fresh inspirations will finally form products through high degree communications, sane arguments, furious discussions and mutual enjoyments.

(3) Educational training. The educational training is propitious to widen the transmitted channel of knowledge. Through taking part in the training project together, managers from different departments in the enterprise can develop formal and informal communications and establish close human relation network. The research of training project in Xerox Company shows that most skills learned by technical commissaries who take part in the training are not from formal training tutorial, but from some activities outside the relative domains, such as the participation to solve the actual problems and informal discussions with colleagues. In fact, when technical commissaries drink coffee, have lunch and solve difficult problems, their experiences told each other have very important meanings for their individual learning.

(4) Practice community. The practice community means the team of knowledge communication and sharing composed voluntarily by those employees with special specialties or works. The knowledge transfer process in the practice community can be looked as a fine circulation of "communication- trust- learning- sharing". For example, except for some directors, most members is voluntary to take part in the practice community of Xerox Company, and members of the community are from various units, and they have diversiform backgrounds, and the knowledge leader is produced according to the actual problem by community members, and the high degree trust and communication exist among members, and though members are good at utilizing information technology, they will communicate usually face to face, and whatever the knowledge they have learned themselves or knowledge from exterior, they will share with community members to the sky.

\section{Advices to promote enterprise knowledge sharing}

Because of the character differences between explicit knowledge and tacit knowledge, their transfer modes are different. However, that doesn't mean the insulation of these two modes. On the one hand, the electrical spread needs powerful complement of human communication. The communication among persons can establish fine relations with mutual trusts face to face, and drive the spread of explicit knowledge through information technology. On the other hand, the electrical spread offers guide for the transfer of the tacit knowledge. Through the information knowledge loads explicit knowledge, but it can indicate the owner of the tacit knowledge as a guider. Inquirers can find the potential owner of the tacit knowledge through database, electrical forum and other information system, and then obtain the tacit knowledge what they need through individual communications face to face. To really realize knowledge sharing, enterprises must exactly treat the relation between the electrical spread and human communication. Just as the explicit knowledge and tacit knowledge compose the knowledge integration together and they supplement each other, the information technology which promotes the spread of explicit knowledge and the human communication which promotes the spread of tacit knowledge also supplement each other. Of course, because the enterprise characters, scales and competitive modes are not same, their knowledge transfer modes will be different. 
(1) For the enterprise in the mature industry, the emphasis of knowledge transfer is the repeat use of "standard knowledge". Once the knowledge turns into the information-based form, i.e. the knowledge is stored in the knowledge repertory by the letter form, so the enterprise needs not modify when it use the knowledge every time and can acquire profits in the scale that enterprise repeatedly use knowledge. Therefore, the enterprise in the mature industry should emphasize the construction of knowledge base. Of course, conference and forum, employee training and cross-functional team are same important to the knowledge transfer for all types of enterprise.

(2) For the enterprises in the budding industry, aiming at the demand of special customer, their products and services can not achieve standardization, and the project manager must consult experts' opinions to deepen the understand to the essential of the problem, and the employees what they need are experts who possess high degree of originality and can solve problems, and discussions, brain storm and repeating consultation are especially important. Because the knowledge in the budding term is not standardized, the knowledge base is difficult to be established, and because the look and search of "expert knowledge" are usually needed, the function of "knowledge map" is very important.

(3) For the enterprises in the growth industry, their products and services aim at popular demands, and the knowledge is not like the standardization of mutual industry and the speciality of budding industry, and only continual innovation can win by the quality and function of difference. Therefore, these sorts of enterprise need the knowledge groups who are willing to share knowledge and are good at integrate originalities. For the construction of network, more interactions, more communications, more volunteers, more specializations and more favors should be presented, which can not only share information, but can share knowledge and creation activity, i.e. it can not only make for the transfer of explicit knowledge, but be propitious to the transfer of tacit knowledge, and this sort of information system is called as "knowledge community". The knowledge community is the knowledge sharing team composed by employees voluntarily or spontaneously (or half-voluntarily or half-spontaneously). The operation of knowledge community is based on the knowledge base, for example, for the knowledge community of Xerox Company, community members can find their knowledge what they want through the knowledge base, and communicate each other on the community web, and also perform knowledge communication with close distance face to face periodically or at will. Thus it can be seen that the enterprises in the growth industry should emphasize the cultivation of knowledge community.

\section{References}

Simonin, B.L. (1999). Ambiguity and the Process of Knowledge Transfer in Strategic Alliances. Strategic Management Journal.

Szulanski, G. (1996). Exploring Internal Stickiness: Impediments to the Transfer of Best Practice within the Firm. Strategic Management Journal. 